\title{
ANALISIS PERBANDINGAN UNJUK KERJA SISTEM PENYEIMBANG BEBAN WEB SERVER DENGAN HAPROXY DAN POUND LINKS
}

Dite Ardhian $^{1)}$, Adian Fatchur Rochim ${ }^{2)}$, Eko Didik Widianto ${ }^{2)}$

Program Studi Sistem Komputer, Fakultas Teknik, Universitas Diponegoro,

Jln. Prof. Sudharto, Tembalang, Semarang, Indonesia

email : diteardhian@yahoo.co.id

\begin{abstract}
The development of internet technology has many organizations that expanded service website. Initially used single web server that is accessible to everyone through the Internet, but when the number of users that access the web server is very much the traffic load to the web server and the web server anyway. It is necessary for the optimization of web servers to cope with the overload received by the web server when traffic is high.

Methodology of this final project research include the study of literature, system design, and testing of the system. Methods from the literature reference books related as well as from several sources the internet. The design of this thesis uses Haproxy and Pound Links as a load balancing web server. The end of this reaserch is testing the network system, where the system will be tested this stage so as to create a web server system that is reliable and safe.

The result is a web server system that can be accessed by many user simultaneously rapidly as load balancing Haproxy and Pound Links system which is set up as front-end web server performance so as to create a web server that has performance and high availability
\end{abstract}

Keywords : Performance, Web Server, System, Load Balancing

\section{PENDAHULUAN}

\subsection{Latar Belakang}

Perkembangan teknologi web harus didukung pula dengan infrastruktur yang baik dan berkecepatan tinggi agar berbagai kebutuhan tersebut dapat terpenuhi dengan baik. Peningkatan permintaan pada situs, menyebabkan web server sibuk menjawab permintaan klien dan terkadang pula web server mengalami server mati atau kegagalan server jika terlalu banyak permintaan sehingga web server tidak dapat menanganinya. Hal ini akan merugikan pihak yang mempercayakan situsnya pada suatu web server, karena situs-situs tersebut tidak dapat diakses untuk sementara waktu. Parameter seperti waktu tanggap, kemerataan beban dan keberhasilan pelayanan merupakan parameter yang menentukan kinerja suatu web server.

Salah satu mekanisme untuk lebih mengoptimalkan penggunaan sumber daya yang ada adalah dengan mekanisme load balancing yang akan menyeimbangkan beban dari seluruh server yang ada pada cluster. Melalui penggunaan mekanisme penyeimbang beban, permintaan koneksi HTTP yang datang pada web server akan ditangani oleh server dengan kondisi yang paling baik, dimana pemilihan tersebut dilakukan dengan sistem prioritas web server.

Ada beberapa metode penyeimbang beban web server. Salah satu metode penyeimbang beban web dapat menggunakan reverse proxy, yaitu proxy yang memiliki maksud yang berkebalikan dengan forward proxy yaitu menjadi perantara user-user di internet terhadap akses ke web-web server yang berada pada LAN, sehingga seolaholah user di internet mengakses langsung web server yang dimaksud padahal sesungguhnya user di internet mengakses web-web server yang terdapat di LAN melalui reverse proxy tersebut. Tentunya komputer yang bertindak sebagai reverse proxy tersebut memiliki IP publik sehingga dapat diakses dari Internet. Salah satu contoh perangkat lunak opensource yang menggunakan metode reverse proxy adalah Haproxy dan Pound Links, kedua perangkat lunak tersebut dapat digunakan sebagai penyeimbang beban web server dan caching web server sehingga akses ke web menjadi cepat dan beban web server menjadi seimbang.

\subsection{Tujuan}

Menguji dan menganalisis penggunaan program opensource Haproxy dan Pound Links, mekanisme kerja sistem penyeimbang beban web server, dan perbandingan unjuk kerja sistem penyeimbang beban web server dengan Haproxy dan Pound Links.

\subsection{Pembatasan Masalah} berikut. 
1. Mesin Server Haproxy dan Pound Links menggunakan sistem operasi distro Ubuntu server 12.04 .

2. Menggunakan replikasi basis data MySQL untuk update basis data web server.

3. Menggunakan metode sinkronisasi Unison automatis untuk update dokumen WWW web server.

4. $\quad$ Menggunakan web server Apache2.

5. Sistem penyeimbang beban ini dijalankan di server fisik bukan virtual.

\section{DASAR TEORI}

\subsection{Sistem Penyeimbang Beban (Load}

\section{balancing)}

Penyeimbang beban (Load Balancing) adalah suatu proses dan teknologi yang mendistribusikan trafik situs di antara beberapa server dengan menggunakan perangkat berbasis jaringan. Sesuai kriteria dasar penyeimbang beban proses ini mampu mengurangi beban kerja setiap server sehingga tidak ada server yang kelebihan beban, memungkinkan server untuk menggunakan bandwidth yang tersedia secara lebih efektif, dan menyediakan akses yang cepat ke situs-situs yang di-hosting. Penyeimbang beban dapat diimplementasikan dengan menggunakan perangkat keras, perangkat lunak, atau gabungan keduanya.

Penyeimbang beban merupakan proses fleksibel yang dapat diciptakan dengan berbagai cara dan metode. Proses ini tidak dapat dilakukan oleh sebuah perangkat tertentu atau sebuah perangkat lunak khusus saja. Cukup banyak cara dan pilihan untuk mendapatkan jaringan yang dilengkapi dengan sistem penyeimbang beban. Cara kerja dan prosesnya berdeda-beda satu sama lainnya. Pada dasarnya penyeimbang beban adalah suatu teknik yang digunakan untuk memisahkan antara dua atau banyak link jaringan. Dengan mempunyai banyak link maka optimalisasi utilisasi sumber daya, throughput atau waktu respon akan semakin baik karena mempunyai lebih dari satu link yang bisa saling mem-backup pada saat jaringan mati dan menjadi cepat pada saat jaringan normal jika memerlukan realibilitas tinggi yang memerlukan $100 \%$ koneksi uptime dan yang menginginkan koneksi upstream yang berbeda dan dibuat saling mem-backup. ${ }^{[6]}$

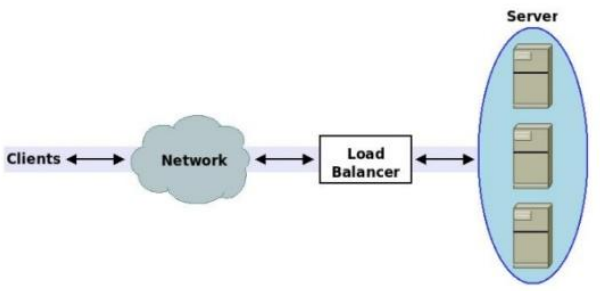

Gambar 1 Skema Sistem penyeimbang beban ${ }^{[6]}$

\subsection{Reverse proxy}

Pengelompokan sistem penyeimbang beban terdapat beberapa jenis terdapat proxy yang merupakan bagian dari sistem penyeimbang beban yang bisa bertindak sebagai pembagi beban, filtering, dan caching. Proxy adalah sebuah sistem komputer atau program aplikasi yang melayani permintaan dari klien dengan meminta layanan ke server lain. Proxy server memiliki 3 fungsi utama yaitu :

1. Connection sharing : perantara klien dan server.

2. Filtering : bekerja pada layer aplikasi yang dapat mem-block paket-paket tertentu.

3. Caching : mampu menyimpan informasi yang pernah di akses dari server-server.

Proxy di bagi menjadi 2 yaitu forward proxy dan reverse proxy. Proxy forward adalah proxy yang meneruskan data ke host tujuan. Reverse proxy adalah proxy yang menampung permintaan klien dari Internet dan meneruskan ke server-server yang berada satu LAN (local area network) dengan proxy tersebut. Aplikasi yang berfungsi sebagai reverse proxy contohnya adalah Haproxy dan Pound Links.

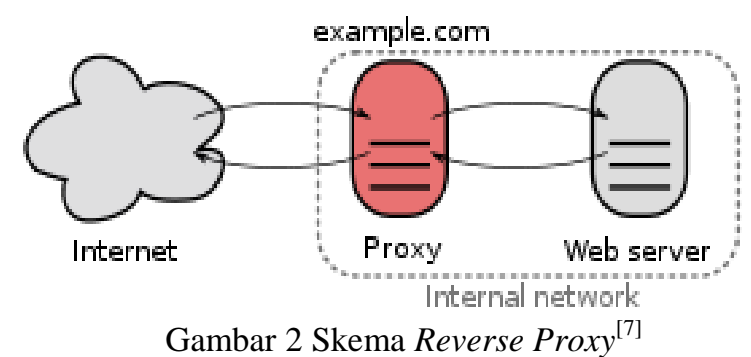

Server proxy adalah server yang bertindak sebagai perantara untuk melayani permintaan dari klien yang mencari sumber daya dari server lain di dalam jaringan komputer. Seorang klien terhubung ke server proxy dan meminta beberapa layanan, seperti sambungan file, halaman web, atau sumber yang lain yang tersedia dari server yang berbeda. ${ }^{[7]}$ 


\subsubsection{Haproxy}

Haproxy adalah produk opensource yg mendukung keperluan penyeimbang beban dan failover web server, banyak digunakan untuk keperluan reverse proxy di site-site yang trafik hariannya tinggi. Pada Haproxy memiliki beberapa parameter di dalamnya yaitu sebagai berikut. ${ }^{[8]}$

1. Global parameter : berisi parameter manajemen proses dan keamanan, tuning kinerja, debugging, dan userlist

2. Proxy

3. Konfigurasi Server

4. Manipulasi HTTP

5. Accesslist

6. Logging

7. Statistik dan monitoring

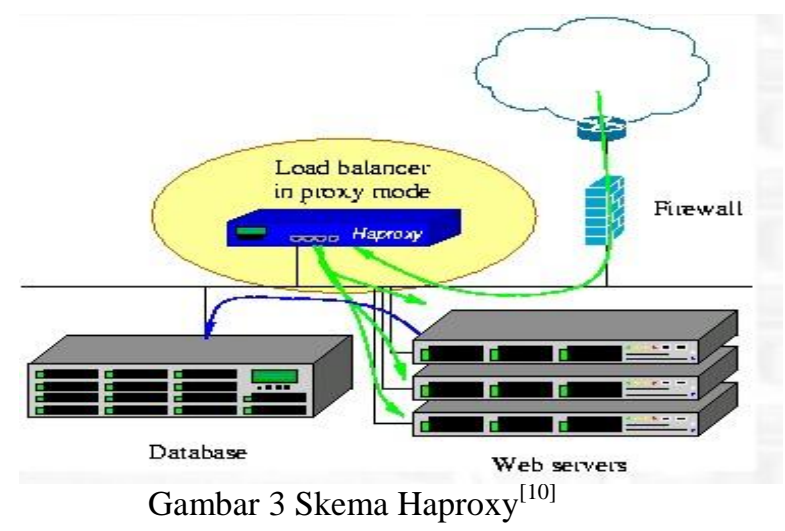

\subsubsection{Pound Links}

Pound merupakan program reverse proxy, penyeimbang beban (load balancer), dan http(s) front end pada web server. Pound dikembangkan untuk memungkinkan mendistribusikan beban antara web server dan dapat juga meng-enkripsi dan dekripsi paket data yang akan dilewatkan yaitu SSL. Pound merupakan program opensource.[11]

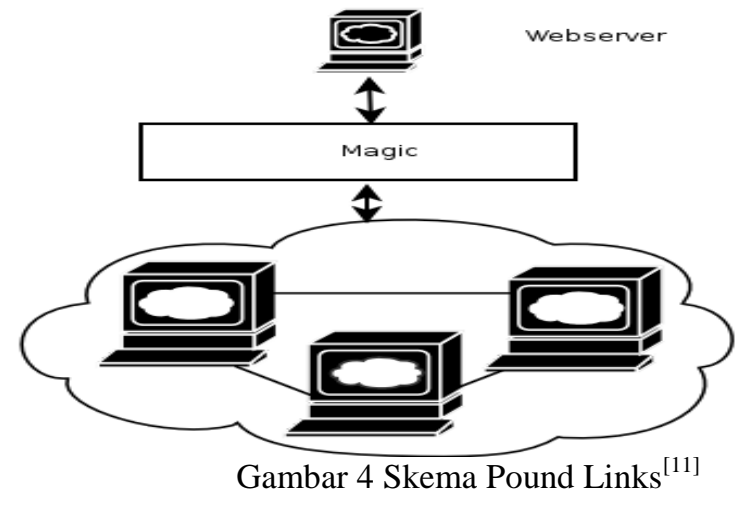

Beberapa fungsi yang dari Pound Links.

1. Reverse proxy

2. Load balancer (pembagi beban server)
3. SSL (enkripsi/dekripsi paket data)

4. Menggunakan protokol HTTP

5. Fail over system saat terjadi kegagalan server

6. Membagi beban berdasarkan URL

\section{Web Server}

Server web dapat merujuk baik pada perangkat keras ataupun perangkat lunak. Server web menyediakan layanan akses kepada pengguna melalui protokol komunikasi HTTP atau HTTPS.

Penggunaan paling umum server web adalah untuk menempatkan situs web. Pada prakteknya penggunaannya diperluas sebagai tempat peyimpanan data ataupun untuk menjalankan sejumlah aplikasi kelas bisnis. Fungsi utama sebuah server web untuk mentransfer berkas atas permintaan pengguna melalui protokol komunikasi yang telah ditentukan dan mentransfer seluruh aspek pemberkasan dalam sebuah halaman web yang terkait; termasuk di dalamnya teks, gambar, video, atau lainnya. Kriteria dasar web server berjalan dengan baik adalah dengan terjalinnya komunikasi misalnya protokol HTTP/HTTPS dari server ke klien atau sebaliknya tanpa ada data yang hilang.

\subsection{Sinkronisasi Automatis Menggunakan Unison}

Unison adalah tool untuk transfer dan sinkronisasi file atau tree (struktur direktori dan file) secara dua arah, baik transfer lokal (di sistem yang sama) maupun remote (jaringan/internet). Unison merupakan tools kecil yang powerful karena bisa bertindak sebagai server sekaligus sebagai klien. ${ }^{[15]}$

\section{$2.4 \quad$ Replikasi MySQL}

MySQL juga mendukung fungsi replikasi. Replikasi di MySQL merupakan proses dinamis dari sinkronisasi data antara server (master) basis data utama dengan satu atau lebih sekunder (slave) server basis data secara real-time. Dengan replikasi, data masih dapat dipulihkan dari salah satu server sekunder jika server utama gagal, karena adanya salinan dari satu atau lebih basis data tadi. ${ }^{[12]}$

\section{PERANCANGAN SISTEM}

Perancangan sistem ini dibutuhkan tiga server yaitu 2 server untuk Web server dan 1 server sebagai front-end dari web server yang fungsi nya sebagai penyeimbang beban web server .Web server dan server penyeimbang 
beban berada pada jaringan lokal, alamat IP kedua web server adalah IP lokal untuk mengamankan web server karena IP nya tidak dapat diakses langsung melalui Internet, sedangkan server penyeimbang beban memiliki 2 antar muka yang terhubung dengan kedua web server dengan IP lokal dan antar muka satu lagi terhubung dengan internet/ jaringan publik yang dapat diakses dari luar jaringan lokal.

Cara server penyeimbang beban memilih web server mana yang dipilih untuk melayani permintaan user/klien ditentukan oleh konfigurasi aplikasi pada server penyeimbang beban. Ada beberapa algoritma dan parameter yang dapat menentukan pembagian beban/pemilihan web server tersebut. Skema physical topologi dapat dilihat pada gambar 5 .

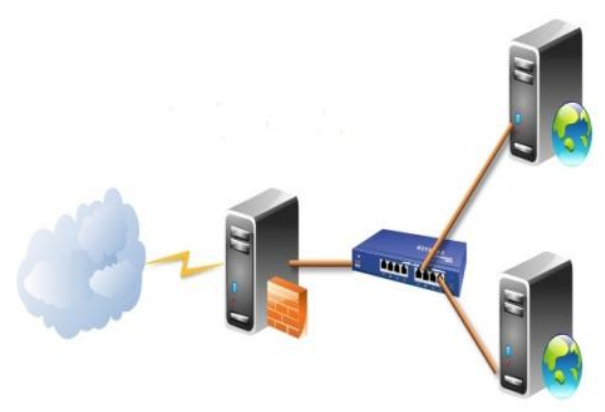

Gambar 5 Skema Physical Topologi

Web server menggunakan mekanisme replikasi basis data MySQL yaitu penduplikasian isi basis data yang berada pada web server 1 dan web server 2 , hal ini bertujuan agar database pada web server 1 dapat meng-update data ke web server 2 dan sebaliknya sehingga tidak terdapat informasi yang salah atau berbeda pada kedua database di kedua web server tersebut sehingga memudahkan dalam pengentrian data.

Web server juga mengggunakan mekanisme mensinkronkan data-data web server 1 dan web server 2 sehingga data akan sama di kedua web server jika ada update dari web server 1 dan sebaliknya.

Jaringan terbagi menjadi dua bagian yaitu jaringan internal dan eksternal. Web server keduanya di beri IP lokal dan penyeimbang beban menggunakan dua buah IP di dua antar muka LAN dan antar muka Internet. Skema logical topologi dapat dilihat pada gambar 6 .

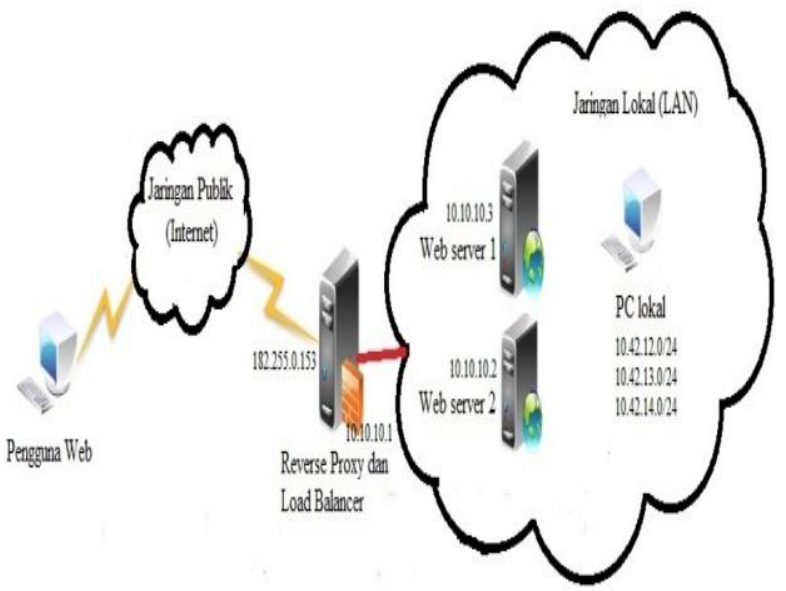

Gambar 6 Skema Logical Topologi

\section{IMPLEMENTASI DAN PENGUJIAN}

Implementasi dilakukan dengan membuat layanan-layanan seperti pada perancangan. Dimulai dengan penanaman sistem operasi pada masing-masing server sampai dengan implementasi aplikasi-aplikasi yang diperlukan oleh masing-masing server. Setelah semua paket telah terpasang, maka hal terpenting yang harus dilakukan adalah melakukan konfigurasi agar semua proses proses dapat berjalan dengan kinerja yang baik.

\subsection{Implementasi dan Konfigurasi Haproxy dan Pound Links}

Implementasi dilakukan pada server frontend sebagai penyeimbang beban yang akan membagi beban dan meneruskan trafik ke web server di back-end. Parameter pengaturan penyeimbang beban perlu disesuaikan sesuai dengan kebutuhan seperti menggunakan metode penyeimbang beban round robin, pemberian prioritas pada server back-end, dan lain-lain

\subsection{Implementasi dan Konfigurasi Web Server \\ Web server perlu diinstall Apache web} server, PHP5, php5-dev, dan MySQL server. Apache web server bertugas menerima dan membalas permintaan situs yang datang dari klien di web server. PHP5 berfungsi mendukung bahasa pemrograman PHP pada web server. Php5-dev digunakan sebagai syarat implementasi PHP Accelerator dengan perangkat lunak eAccelerator. MySQL server sebagai basis data berfungsi sebagai syarat mengimplementasi Joomla dan Wordpress. 


\subsection{Implementasi dan Konfigurasi Unison}

Unison diterapkan pada kedua web server. Unison yang digunakan adalah Unison automatis dimana web server yang datanya tidak update maka data tersebut di replace dengan data yang update.

\subsection{Implementasi dan Konfigurasi} Replikasi MySQL

Replikasi basis data MySQL yaitu penduplikasian isi database yang berada pada web server 1 dan web server 2 , hal ini bertujuan agar basis data pada web server 1 dapat meng-update data ke web server 2 dan sebaliknya sehingga tidak terdapat informasi yang salah atau berbeda pada kedua basis data di kedua web server tersebut sehingga memudahkan dalam pengentrian data.

\subsection{Hasil pengujian dari Sistem Load Balancing}

Pengujian Haproxy, Pound Links, LAMP, dan Unison dilakukan dengan server Community UNDIP hostname community.undip.ac.id dengan tampilan halaman web pada gambar 7 .

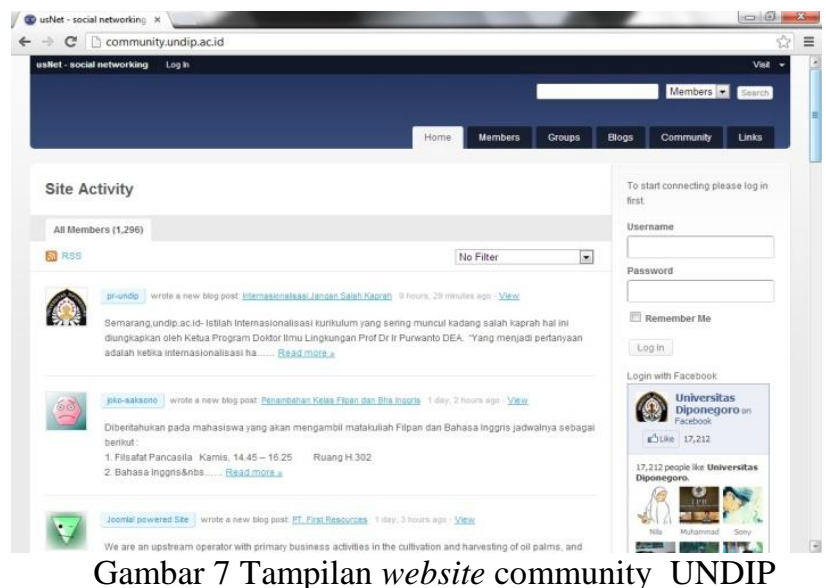

Hasil pengujian di atas, penggunaan lebar jalur data tidak terlalu besar dari lebar jalur data maksimal, ini disebabkan penggunaan Unison untuk sinkronisasi yang akan melakukan update jika ada event update sehingga tidak menghabiskan lebar jalur data antara web server.

Permintaan dari pengguna cukup besar yang diakumulasikan pada besarnya penggunaan lebar jalur data namun, kedua web server tersebut masih berjalan stabil dan dapat diakses pengguna dengan lancar.

Penggunaan penyeimbang beban Haproxy sedikit lebih optimal dibandingkan mengunakan
Pound Links dilihat dari throughput dan waktu respon.

Tabel 1 Hasil pengujian Httperf

\begin{tabular}{|l|l|l|l|l|}
\hline $\begin{array}{l}\text { Penyeimbang } \\
\text { beban }\end{array}$ & $\begin{array}{l}\text { Rata } \\
\text { Konek } \\
\text { si }\end{array}$ & $\begin{array}{l}\text { Rata } \\
\text { permint } \\
\text { aan }\end{array}$ & $\begin{array}{l}\text { Waktu } \\
\text { Respo } \\
\mathrm{n}(\mathrm{ms})\end{array}$ & Throughput \\
\hline Haproxy & $\begin{array}{l}1825.5 \\
\text { conn/s }\end{array}$ & $\begin{array}{l}1769.1 \\
\mathrm{req} / \mathrm{s}\end{array}$ & 134.2 & $830.9 \mathrm{~KB} / \mathrm{s}$ \\
\hline Pound Links & $\begin{array}{l}1497.7 \\
\text { conn/s }\end{array}$ & $\begin{array}{l}1483.4 \\
\mathrm{req} / \mathrm{s}\end{array}$ & 234.6 & $675.2 \mathrm{~KB} / \mathrm{s}$ \\
\hline IPTables & $\begin{array}{l}173.4 \\
\text { conn/s }\end{array}$ & $\begin{array}{l}100.1 \\
\mathrm{req} / \mathrm{s}\end{array}$ & 2600.8 & $36.1 \mathrm{~KB} / \mathrm{s}$ \\
\hline
\end{tabular}

Tabel 2 Hasil pengujian Webbench

\begin{tabular}{|l|l|l|}
\hline $\begin{array}{l}\text { Penyeimbang } \\
\text { beban }\end{array}$ & Pages/min & Throughput \\
\hline Haproxy & 193972 & 654350 bytes/sec \\
\hline Pound Links & 117218 & 542725 bytes/sec \\
\hline IPTables & 16640 & 400563 butes/sec \\
\hline
\end{tabular}

Pada tabel 1 dan tabel 2 menunjukan

Penyeimbang beban Haproxy sedikit lebih unggul dari Pound Links maupun Penyeimbang beban menggunakan IPTables yang telah di teliti oleh peneliti sebelumnya. Sehingga Haproxy dapat digunakan sebagai pilihan pertama penggunaan Penyeimbang beban web server.

\section{PENUTUP}

\subsection{Kesimpulan}

1. Kinerja sistem penyeimbang beban Haproxy maupun Pound Links pada Ubuntu server 12.04 dapat membagi beban CPU, memori dan trafik.

2. Sistem penyeimbang beban ini menggunakan failover mode saat salah satu server mengalami kegagalan server maka layanan web tetap dapat diakses klien.

3. Data yang dikirimkan oleh server ke klien baik pada sistem penyeimbang beban Haproxy maupun Pound Links tidak rusak maupun hilang.

4. Web server menjadi aman karena IP nya menggunakan IP lokal yang tidak dapat di akses maupun di traceroute secara langsung dari Internet. 
5. Replikasi dua arah basis data MySQL berfungsi untuk update basis data server secara realtime.

6. Sinkronisasi menggunakan Unison memiliki keunggulan yaitu hemat bandwidth.

7. Sistem penyeimbang beban menggunakan Haproxy memiliki keunggulan dibanding Pound Links dari parameter waktu respon $70 \%$ lebih cepat, throughput 20\% lebih besar dan akses halaman per menit $60 \%$ lebih banyak.

\subsection{Saran}

Adapun saran yang dapat diberikan sehubungan dengan pelaksanaan penelitian ini adalah sebagai berikut.

1. Sistem penyeimbang beban yang yang telah digunakan dapat diterapkan pula untuk membuat sistem penyeimbang beban web server UNDIP khususnya saat diperlukan layanan web server dengan jumlah akses ke web server sangat tinggi agar layanan dapat teratasi dengan baik.

2. Sistem penyeimbang beban ini dapat dikembangkan lagi dengan jumlah web server yang lebih banyak.

3. Sistem penyeimbang beban ini dapat dikembangkan lagi tidak hanya di implementasikan pada dedicated server tetapi bisa juga pada virtual server.

\section{DAFTAR PUSTAKA}

[1] Abdullah, A, SNMP Simamora, dan HR Andrian. Implementasi dan Analisa Load Balancing pada suatu Web Server Lokal. Politeknik Telkom, 2010.

[2] Bourke, T. Server Load Balancing. O'Reilly, 2001

[3] Lukitasari, Desy dan AF Oklilas. Analisis Perbandingan Load Balancing Web Server Tunggal Dengan Web Server Cluster Menggunakan Linux Virtual Server. Universitas Sriwijaya, 2010.

[4] Nurhatta, Andy Purnama. Sistem Penyeimbang Beban Web Server Dengan IPTABLES. Tugas Akhir S-1, Universitas Diponegoro, Semarang, 2012.

[5] Rijayana,Iwan. Teknologi Load Balancing Untuk Mengatasi Beban Server, SNATI, Yogyakarta, 2005.
[6] Sagala, Muhfi Asbin. Implementasi Load Balancing Pada Web Server. Tugas Akhir S-1, Universitas Sumatera Utara, Medan, 2010.

[7] Stricek, Art. A Reverse Proxy Is A Proxy By Any Other Name. Paper Sans Institude, 2002.

[8] --,Haproxy Documentation, http://code.google.com/p/haproxy-docs 25 Juni 2012, 20.00 WIB

[9] --,HTTP,

http://id.wikipedia.org/wiki/Protokol_Transfer _Hiperteks 12 Juni 2012, 21.00 WIB

[10] --,Httperf,

http://www.hpl.hp.com/research/linux/httperf/ httperf-man-0.9.txt Agustus 2012, 22.30 WIB

[11] --, Pound, http://www.apsis.ch/pound/ 25 Juni 2012, 23.00 WIB

[12] --,Replication Reference Manual 2012, http://google.com/MySQL $5.0 \quad$ Replication Reference Manual 11 Agustus 2012, 09.00 WIB

[13] --,Webbench http://down.chinaz.com/server/201202/1671_1 .htm 2 Februari 2013, 12.00 WIB

[14] --,Wikipedia Proxy Server, http://en.wikipedia.org/wiki/Proxy_server 22 Agustus 2012, 21.00 WIB

[15] --,Wikipedia Unison, http://id.wikipedia.org/wiki/Unison_(file_sync hronizer) 4 Januari 2013, $13.40 \mathrm{WIB}$

\section{BIODATA}

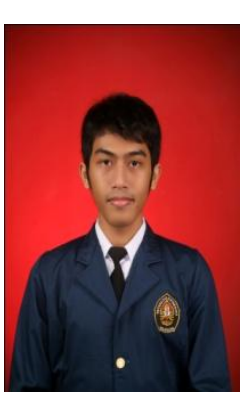

Dite Ardhian, lahir di Semarang 9 Juni 1990. Menempuh pendidikan dasar di SD N Siliwangi Semarang. Melanjutkan ke SMP N 1 Semarang, Dan Pendidikan tigkat atas di SMA N 1 Semarang, lulus tahun 2008. Dari tahun 2008 sampai saat ini tengah menyelesaikan pendidikan Strata Satu di Program Studi Teknik Sistem Komputer, Universitas Diponegoro, Semarang, Indonesia Angkatan Tahun 2008. 